Chymia

Annual Studies in the History of Chemistry. Tenney L. Davis, Editor-in-Chief. Vol. 1. (Edgar F. Smith Memorial Collection, University of Pennsylvania.) Pp. xiv $+190+16$ plates. (Philadelphia : University of Pennsylvania Press; London: Oxford University Press, 1948.) 3.50 dollars.

$\mathrm{T}$ HIS handsome volume, which is a worthy memorial to the late Prof. Edgar F. Smith, well known for his publications in the field of the history of chemistry, contains fourteen articles covering various aspects of the subject. All but one are in English. After a foreword, the essays take up the subjects of Frederick Accum, C. A. Browne, an English alchemical poem, Thomas Thomson, French chemists about 1840 , Mendeléeff, potassium chlorate in pyrotechny, the early history of ealomel, the concepts of substance and element, the water controversy, Scottish alchemy, the Karlsruhe Congress, and Dulong. There are several plates, and the text is unusually well printed, which, with the attractive binding, makes it a pleasure to read the volume. It is proposed to issue a volume annually, and if further volumes are as good as the first, the editor-in-chief, Prof. Tenney L. Davis, whose own historical publications set a very high standard, may well feel satisfied. All concerned in the production deserve the thanks of chemists who are interested in the history of their subject. The series should be acquired by all chemical libraries, and is a notable contribution to scientific literature.

\section{Chemical Synonyms and Trade Names}

A Dictionary and Commercial Handbook. By William Gardner. Fifth edition, revised and enlarged by Edward I. Cooke. Pp. viii +558 . (Kingston Hill : Technical Press, Ltd., 1948.) 50s. net.

$\mathrm{T}$ $\mathrm{HE}$ only satisfactory method of reviewing a reference book such as this is to make continued use of it over a period of time, for only in that way can its value really be determined. Following this course, the reviewer has been surprised at the frequency with which trade names turn up during the course of a day, and has been equally surprised at the completeness with which the dictionary has met all demands made upon it. Only very occasionally has it failed; for example, it makes no mention of sulpha drugs, such as sulphapyridine; but the constancy with which it succeeds makes its failure a notable event.

The book will prove of great value to all who have to deal with chemistry and chemicals, and its information is not confined to any particular field of chemistry but embraces all. It is well printed on good paper and is stoutly bound, as a reference book should be.

\section{Organic Syntheses}

An Annual Publication of Satisfactory Methods for the Preparation of Organic Chemicals. By R. L. Shriner, Editor-in-Chief. Vol. 27. Pp. vi +121 . (New York: John Wiley and Sons, Inc.; London: Chapman and Hall, Ltd., 1947.) 13s. $6 d$. net.

$\mathrm{T}$ $O$ the large number of organic chemicals for which reliable preparative methods have been given in this invaluable publication a further list of thirty-nine is now added. As typical examples may be mentioned 3,5-dimethyl-2-cyclohexen-1-one from acetaldehyde and acetoacetic ester, ethyl $\alpha$-isopropylacetoacetate from isopropyl alcohol and acetoacetic ester in presence of boron fluoride, 3-penten-2-ol from magnesium methyl chloride and crotonaldehyde, stearolic acid from methyl oleate, and tetraiodoph. thalic anhydride from phthalic anhydride and iodine in presence of fuming sulphuric acid. The statement of directions and precautions, the bibliography for each preparation, and the printing of text and formulæ are all admirable and remarkably free from errors. The cumulative index covers volumes $20-27$.

$$
\text { J. R. }
$$

The Rare-Earth Elements and their Compounds By Prof. Don M. Yost, Horace Russell, Jr., and Asst. Prof. Clifford S. Garner. Pp. ix + 92. (New York: John Wiley and Sons, Inc.; London: Chapman and Hall, Ltd., 1947.) 15s. net.

THIS little book on the elements of the rare earth group, or lanthanides as they are now called, contains chapters on $(a)$ electronic structures and oxidation states, $(b)$ magnetic properties, $(c)$ absorption spectra, $(d)$ evidence for the existence of element No. $61,(e)$ separation of the rare earths, and $(f)$ chemical and physical properties of these elements. There is also an appendix on nuclear properties of the rare earth elements. Since the chapters noted above cover only 69 pages, it is inevitable that the subject-matter has been very much condensed, a fact more evident in descriptions of chemical than physical properties. Apart from this limitation, the volume contains much useful and interesting information about this group of elements. The rare earths have received more attention from chemists following the discovery that some of them are formed directly or indirectly in nuclear disintegrations. This book provides a useful introduction to the study of a very interesting series of the chemical elements.

\section{Elements of Nomography}

By Prof. Raymond D. Douglass and Asst. Prof. Douglas P. Adams. Pp. ix +209 . (New York and London: McGraw-Hill Book Co., Inc., 1947.) 3.50 dollars.

TTHAT a straight-edge laid across three coplanar linear scales will serve to express a multilinear functional relation between the indicated scale readings is obvious; if the linear scales are not uniform, more complex relationships can be dealt with. But the step from these simple ideas to the construction of the alignment charts used increasingly in engineering, industry, business and other fields is considerable, and demands skill in design and draughtsmanship as well as in orderly computation. Profs. Douglass and Adams are anxious that the young nomographer should not try to run before he can walk, that he should realize "how small a portion of his entire problem the theoretical solution represents". Thus they begin with a painstaking discussion of seales, occupying six chapters, before starting their discussion of the simpler alignment diagrams in a series of nine short chapters, the last of which deals with the hexagonal diagram for the relation

$$
1 / x+1 / y=1 / z \text {. }
$$

There is a short chapter on the use of a circular nomogram for the relation $x y=z$, and a final lengthy chapter on a variety of more complex alignment diagrams, wherein curved scales are employed.

The casual reader who merely wishes to learn a little about nomograms would probably find the pace of this book too slow. But a novice with some strong incentive urging him to master the topic should profit from the careful and detailed discussion, with its valuable practical illustrations. 